\title{
O MANIFESTO DOS EDUCADORES DE 1959 REVISITADO: EVENTO, NARRATIVAS E DISCURSOS
}

Bruno Bontempi Jr.

I Universidade de São Paulo (USP), São Paulo, Brasil; bontempi@usp.br

\section{Resumo}

Trata-se de análise histórica do manifesto de educadores "Mais uma vez convocados: manifesto ao povo e ao governo" (1959), divulgado em resposta à irrupção de um substitutivo ao projeto de Lei de Diretrizes e Bases da Educação. Examina os alicerces de sua memória, interrogando as razões e os efeitos da predominante explicação por meio de suas relações com o Manifesto dos Pioneiros e a Campanha em Defesa da Escola Pública. Reconstrói eventos, agentes e significados, compreendendo-os como ação coletiva e coordenada de intelectuais para fins políticos determinados. Conclui-se realçando o manifesto em sua especificidade e historicidade, aparando equívocos historiográficos resultantes de repetições sem lastro e abordagens que produziram lacunas em sua compreensão como evento singular. INTELECTUAIS • DOCUMENTOS • IMPRENSA • HISTÓRIA DA EDUCAÇÃO

\section{THE 1959 EDUCATORS' MANIFESTO REVISITED: EVENT, NARRATIVES AND DISCOURSES}

\section{Abstract}

This article presents a historical analysis of the 1959 educators' manifesto "Mais uma vez convocados: manifesto ao povo e ao governo" [Summoned once again: manifesto to the people and to the government], made public in response to the proposal of an amendment to the Draft Law of Bases and Guidelines of Education. The text examines the foundations of the manifesto's memory, investigating the reasons and effects of its predominant explanation through its relations to the Pioneers Manifesto and to the Campaign in Defense of Public School. It reconstructs events, agents and meanings, understanding the manifesto as a collective and coordinated action of intellectuals aiming at certain political ends. It concludes by highlighting the manifesto's specificity and historicity, trimming off historiographical misunderstandings that resulted from baseless repetitions and approaches that left gaps in its understanding as a singular event.

INTELLECTUALS • DOCUMENTS • PRESS • HISTORY OF EDUCATION 


\section{REVISITADO EL MANIFIESTO DE LOS EDUCADORES DE 1959: EVENTO, NARRATIVAS Y DISCURSOS}

\section{Resumen}

Se trata de un análisis histórico del manifiesto de educadores: "Mais uma vez convocados: manifesto ao povo e ao governo" (1959), divulgado como respuesta a la irrupción de un sustituto al proyecto de Ley de Directivas y Bases de la Educación. Examina los cimientos de su memoria, interrogando las razones y los efectos de la predominante explicación por medio de sus relaciones con el Manifiesto de los Pioneros y la Campaña en Defensa de la Escuela Pública. Reconstruye eventos, agentes y significados, comprendiéndolos como una acción colectiva y coordinada de intelectuales para determinados fines políticos. Se concluye realzando el manifiesto en su especificidad e historicidad, recortando equivocaciones historiográficas resultantes de repeticiones sin respaldo y abordajes que produjeron lagunas en su comprensión como evento singular.

INTELECTUALES • DOCUMENTOS • PRENSA • HISTORIA DE LA EDUCACIÓN

\section{LE MANIFESTE DES ÉDUCATEURS DE 1959 REVISITÉ : ÉVÉNEMENT, RÉCITS ET DISCOURS}

\section{Resumé}

Cet article propose une analyse historique du manifeste des éducateurs « Mais uma vez convocados: manifesto ao povo e ao governo» (1959), rédigé en réponse à un substitutif du projet de la Lei de Diretrizes e Bases da Educação. Sont examinés les fondements de sa mémoire en s'interrogeant sur les raisons et les effets de l'explication prédominante, à travers les relations qu' il entretient avec le Manifesto dos Pioneiros et la Campanha em Defesa da Escola Pública. Sont reconstitués les événements, les agents et les significations, tout en envisageant le manifeste comme une action collective et coordonnée d'intellectuels visant des fins politiques spécifiques. En conclusion, le manifeste est reconnu dans sa spécificité et son historicité, en dissipant les équivoques historiographiques qui résultent de répétitions non fondées et d'approches ayant conduit à des erreurs de compréhension quant à sa légitimité en tant qu'événement singulier.

INTELLECTUELS • DOCUMENTS • PRESSE • HISTOIRE DE L'ÉDUCATION 
RATAREI DO DOCUMENTO "MAIS UMA VEZ CONVOCADOS: MANIFESTO AO POVO E AO GOVERNO" (1959), de autoria de Fernando de Azevedo, que contou com o apoio de escritores, cientistas, políticos, professores, estudantes, jornalistas e servidores da administração pública. Respondendo à conjuntura de tramitação da Lei de Diretrizes e Bases da Educação, foi divulgado em órgãos oficiais e em jornais da imprensa comercial de São Paulo e do Rio de Janeiro entre 30 de junho e 5 de julho de 1959. Na oportunidade de revisitá-lo, examino os alicerces historiográficos de sua memória, interrogando as razões e os efeitos da explicação oblíqua, mediante relações com o Manifesto de 1932 e a Campanha em Defesa da Escola Pública. Busquei seu significado como evento único e ato de fala de um coletivo intelectual, ao encarnar seus agentes, destrinçar modos de fazer, sentidos e engajamentos e realçá-lo em sua especificidade e historicidade. ${ }^{1}$

Para a construção do Manifesto de 1959 como ato e produto da interação social de intelectuais e do uso intencional que fizeram da linguagem e seus suportes, recorri a Jean-François Sirinelli e Quentin Skinner. De Sirinelli, acato a definição de "geometria variável" do intelectual, baseada nas acepções ampla e sociocultural, que abarca os criadores e mediadores culturais, e estreita e política, baseada na noção de engajamento. $\mathrm{Na}$ análise desse manifesto, pelo qual um coletivo de educadores fez uso público de sua qualificação para fins políticos, pode-se considerá-lo um amálgama provisório do polimorfo meio intelectual, com variadas modalidades de engajamento, tais como líderes, militantes, mediadores, interlocutores, adesistas, testemunhas (Sirinelli, 2003). Duas ferramentas que o historiador francês oferece ao estudo das relações entre intelectuais e política foram úteis: as noções de sociabilidade e geração. Quanto à primeira, considerei a força agregadora e criativa em torno da qual os intelectuais orbitam e se atraem, constroem identidades e produzem acontecimentos, assim como a sociabilidade assentada em experiências compartilhadas de um repertório composto de lugares de encontros, trocas de correspondências, instituições de formação e atuação, circulação de artigos e adesão a manifestos, vivências e afetos que geram sensibilidades e definem escolhas, dando substância à letra fria das subscrições. Essas práticas sociais, ao transcenderem individualidades e crenças pessoais, ajudam a explicar as complexas e multifatoriais motivações da convergência que marca a irrupção dos intelectuais como corpo político discernível. Quanto à noção de geração, considerei importante discernir, nos três acontecimentos que se implicam na historiografia, as duas gerações envolvidas, com seus específicos engajamentos e papéis. Estive atento à ilusão retrospectiva pela qual se projetam sobre uma geração os significados de efeitos posteriores aos eventos que, antes e durante o processo histórico, fizeram-na emergir (Sirinelli, 1986; Alves, 2012). Por fim, compartilho o valor conferido ao acontecimento singular na narrativa histórica. No caso do Manifesto de 1959, relacionado a um fato estabelecido na história da educação, lancei questionamentos à construção, pela historiografia, do significado perene de seu enunciado e de uma memória acossada pela aglomeração de outros eventos e distorcida pela projeção retrospectiva de uma cultura política.

Quanto a Skinner, assimilei procedimentos com os quais pudesse captar os usos da linguagem para produzir sensibilidades e afetos, tais como alarme, indignação, concordância e adesão. Considerei a imbricação entre a dimensão discursiva do significado, relativa ao sentido e à informação supostamente ligados às palavras e frases, e a dimensão da ação linguística, relativa ao que os enunciadores são capazes de fazer mediante seu uso (Skinner, 2005; Vieira, 2017). Admitindo que um texto escrito e publicado

\footnotetext{
Este artigo é produto de investigações realizadas nos projetos de pesquisa "Intelectuais e pensamento educacional como objetos da história da educação brasileira", financiado pelo Conselho Nacional de Desenvolvimento Científico e Tecnológico (CNPq - Bolsa Produtividade PQ2), processo n. 304757/2017-9; e "Saberes e práticas em fronteiras: por uma história transnacional da educação (1810-...)", financiado pela Fundação de Amparo à Pesquisa do Estado de São Paulo (Fapesp - Projeto temático), processo n. 2018/26699-4.
} 
perfaz um ato intencional e refletido, identifico como o redator e seus coautores usaram a linguagem para representar identidade e coesão, atribuir autoridade à condição intelectual, produzir emoções entre interlocutores e junto à "opinião pública" e selecionar e integrar discursos a um campo de significados. Procedo desse modo com relação aos jornalistas, que nos noticiosos "emolduraram” o manifesto, seus signatários e as notícias com aparatos verbo-visuais dirigidos à massa, conferindo-lhes outros sentidos.

\section{Um evento desidratado}

O Manifesto de 1959 estreou como fato histórico da educação em 1978, primeira edição de História da educação no Brasil (1930-1973), de Otaíza Romanelli (1986). Após definir os contendores como um "punhado de educadores lúcidos" versus "lideranças conservadoras" (1986, p. 176), a autora noticia o surgimento do manifesto, destacando-o como "uma das armas de que dispunham . . . as correntes progressistas” (1986, p. 177) na luta contra a possibilidade de transformação, em lei de diretrizes e bases, de um projeto avesso às pautas liberais e democráticas, supostamente assentadas no projeto original, redigido em 1947 sob a tutela de antigos pioneiros. Nos parágrafos anteriores, Romanelli (1986, p. 179) vinha referindo-se à Campanha em Defesa da Escola Pública, surgida em maio de 1960, para retroceder ao dia $1^{\circ}$ de julho de 1959 e reportar o lançamento de "um segundo Manifesto de educadores", assinado por "189 pessoas, dentre as quais educadores intelectuais e estudantes". A alteração da ordem dos fatos presta-se a explicar o manifesto à luz do movimento subsequente, posto que a autora se ampara nas críticas de Barros (1960) aos fundamentos do projeto de lei das "lideranças conservadoras" (Romanelli, 1986, p. 179), dirigidas, porém, ao projeto apresentado em janeiro de 1960 pela subcomissão da Câmara, e não ao substitutivo que Carlos Lacerda levara ao Parlamento seis meses antes.

O substitutivo sustentava-se na denúncia do pendor monopolista do projeto de lei original (1947) em favor do Estado, contra o qual defendia o direito de escolha das famílias pelas instituições particulares e confessionais. Apoiado nas conclusões do Congresso de Estabelecimentos Particulares de Ensino (Cunha, 1983), pleiteava que o Estado beneficiasse, antes do ensino oficial, a iniciativa privada (Barros, 1960; Romanelli, 1986; Buffa, 1979). Duas semanas antes de sua aparição, uma matéria de $O$ Estado de $S$. Paulo (Oesp) noticiava que o manifesto já estaria "todo redigido, faltando, para sua divulgação, ser datilografado e assinado", e que sua motivação imediata era responder ao substitutivo Lacerda:

A oportunidade de lançamento de um novo manifesto de educadores surgiu da necessidade de se configurar com maiores precisão e objetividade a situação atual e os princípios e tendências da educação no Brasil em face dos debates suscitados pela tramitação, na Câmara Federal, do projeto de lei que fixa as diretrizes e bases da educação nacional e pela apresentação de um substitutivo a esse documento legal. (Manifesto dos educadores em princípio de julho, 1959, junho 20, p. 11). ${ }^{2}$

No dia 23 de junho, o Correio Paulistano publicou trechos de entrevistas com as "autoridades educacionais” Antonio Ferreira de Almeida Jr., que “já estava a par da redação do Manifesto”, e Carlos Correa Mascaro, que "ainda não estava ciente dos termos de redação de seu colega professor Fernando de Azevedo" (Escola pública é o único patrimônio para nossa consolidação democrática, 1959, junho 23, p. 9). Almeida Jr., signatário de 1932 e partícipe das comissões assessoras à Câmara desde 1947, reforçava o que havia dito a matéria do Oesp a respeito da motivação para o lançamento do Manifesto de 1959:

ao apagar das luzes da legislatura precedente houve contra ele [o projeto de lei, de 1947] inesperada oposição, sob a alegação verdadeiramente esdrúxula de que aquela proposição . . . atentava a liberdade de ensino. ... [Mas] essa liberdade perigará . . . se vencer a opinião oposta. Daí a importância excepcional do manifesto. (Escola pública é o único patrimônio para nossa consolidação democrática, 1959, junho 23, p. 9). 
Os educadores vinham a público romper o isolamento do intelectual e reivindicar o "direito de se unirem para fortalecer o seu protesto" e o "direito ao escândalo" (Charle, 1990, p. 8), diante de uma ameaça à educação, patrimônio da civilização, e à democracia, valor universal. $\mathrm{O}$ argumentum ad terrorem aparece à opinião pública antes mesmo da publicação do manifesto, na matéria do Correio Paulistano em que Mascaro afirma:

Os debates travados na Câmara dos Deputados em torno do assunto estão demonstrando que caminhamos a largos passos para uma das crises de mais funestas consequências para o futuro do país.... espera-se que ele [o Manifesto] seja um claro pronunciamento da consciência liberal do Brasil na defesa de um patrimônio, a escola pública brasileira, que é o único com que podemos realmente contar para a consolidação e o aperfeiçoamento da democracia em nossa Pátria. (Escola pública é o único patrimônio para nossa consolidação democrática, 1959, junho 23, p. 9).

Sendo evidente que reagia imediatamente à ameaça acenada pelo substitutivo Lacerda, o manifesto não poderia ter sido, como quer Romanelli (1986), um dos atos de "progressistas" contra a aprovação de um projeto que foi à pauta na legislatura seguinte; em vez disso, como sugere Cunha (1983), ele pode ter criado um clima favorável para a emergência da campanha. Romanelli (1986) pode ter sido induzida a encartar um evento no outro em razão de ter se baseado apenas na coletânea Diretrizes e bases da educação, em que Barros (1960), a título de "antecedentes" da Campanha, incorporou uma cópia do manifesto junto a peças parlamentares e de imprensa. Entretanto, o organizador da obra, ativo combatente da Campanha, não havia assinado o manifesto. A discrepância revela o fato de se tratar de eventos de pautas semelhantes, mas diversos em suas conjunturas, dinâmicas e protagonismos.

A precoce desidratação do manifesto como evento não se deve apenas à sua redução como antecedente da Campanha em Defesa da Escola Pública. "Mais uma vez convocados", como o título anuncia, é sombreado pelo Manifesto dos Pioneiros da Educação Nova (1932). A maioria dos historiadores e filósofos da educação assim o aceita, e um conjunto significativo de obras sobre o Manifesto dos pioneiros menciona o de 1959 como seu herdeiro direto. ${ }^{3}$ No único ensaio que põe em dúvida essa relação, o argumento é frustrante: afirma Warde (2004) que, "seguramente, o título do Manifesto de 1959 não se refere aos 26 signatários do Manifesto de 1932; aliás, daqueles somente 11 assinaram o novo Manifesto, que obteve 178 assinaturas novas...”. À parte a duvidosa veracidade do cômputo, de que tratarei adiante, as biografias revelam que ao menos para oito signatários de 1932 não haveria outra opção, pois nessa ocasião já haviam falecido.

Essa vinculação entre os movimentos esteve presente no momento de irrupção do manifesto como estratégia, com claro objetivo de granjear radicação e legitimidade (J. P. F. Carvalho, 2008), tendo funcionado como atrativo nos veículos de imprensa, antes mesmo de vir à luz. Em matéria da Folha da Manhã, de 18 de junho de 1959, sugestivamente intitulada "Manifesto público de educadores para reafirmação de princípios diante dos problemas educacionais”, lê-se:

Um novo "Manifesto dos Educadores", nos moldes do famoso "Manifesto dos Pioneiros da Educação Nova no Brasil” [sic], lançado em 1932, será dado a público brevemente no país .... O documento receberá a assinatura não só dos subscritores do manifesto de 32 , mas também de outros educadores, professores, estudantes e demais pessoas de vários estados brasileiros, preocupados com os destinos da Educação no país. (Manifesto público dos educadores para reafirmação de princípios diante dos problemas educacionais, 1959, junho 18, s.p.).

3 Essa interpretação prevalece no número especial "O manifesto educador: os pioneiros 80 anos depois", da Revista Brasileira de Estudos Pedagógicos. Ressalto a instigante abordagem de Xavier (2015), na qual revela como a geração de Florestan Fernandes e Darcy Ribeiro apropriou-se criticamente e, à luz de suas convicções e de outro contexto, conferiu significados outros às pautas e conceitos do Manifesto de 1932. 
Ao ser publicado no Diário de Notícias, o manifesto é anunciado por um título inexistente no original, que reforça a continuidade entre os manifestos: "Nova etapa no movimento de reconstrução nacional" (Manifesto dos educadores mais uma vez convocados, 1959, julho 2, p. 6). Paradoxalmente, a vinculação à lendária luta, que aos contemporâneos pode ter fortalecido a causa, terminou por enfraquecer o manifesto como evento na narrativa histórica da educação brasileira. Ao designá-lo como "um segundo Manifesto de educadores", Romanelli (1986, p. 179) abriu caminho para converter essa estratégia em fato. Comprimido, enfim, entre dois eventos, o manifesto foi depurado de algumas motivações e efeitos; em contrapartida, ganhou significados extrínsecos.

\section{Assinaturas e gerações: questões polêmicas}

O manifesto foi a público em 30 de junho de 1959, na 68ª sessão da Câmara dos Deputados, pelo deputado udenista Luís Viana Filho. No dia seguinte, foi publicado no Diário do Congresso Nacional (1959, julho 1) e nos Anais da Câmara dos Deputados (1959, julho 1), precedido pela fala do parlamentar. Em ambas as publicações, contam-se 66 assinaturas. No mesmo dia $1^{\circ}$ de julho, apareceu em $O$ Estado de S. Paulo, com 15 novas assinaturas, que totalizariam 81 , se não houvessem desaparecido cinco. A lista do Oesp contém, portanto, 77 nomes. No Diário de Notícias, de 2 de julho, o número se eleva a 133. Também nesse dia, foi noticiado no Jornal do Commercio, do Rio de Janeiro, com 88 assinaturas (Mea culpa perante o povo e a mocidade, 1959, julho 2, p. 1) e, no mesmo periódico, estampado a 5 de julho, já sem as assinaturas (Por um ensino público obrigatório e gratuito, 1959, julho 5, p. 8). Adiante, foi reproduzido na Revista Brasileira de Estudos Pedagógicos (Azevedo, 1959), em volume de abril a junho - data retroativa -, subscrito por 164 nomes, e como anexo ao livro Memórias, de Paschoal Lemme (1988). Para complicar, uma edição do Ministério da Educação (2010), contendo os manifestos de 1932 e 1959, registrou 161 nomes, com consideráveis discrepâncias, sem informar a versão original.

A reiterada informação (Romanelli, 1986; Warde, 2004; Bomeny, 2019) de que o número de signatários tenha sido 189 não tem sustentação. Ao serem coligidas as fontes, esse número não corresponde às listas de junho e julho de 1959, tampouco à publicada na RBEP. Apenas na coletânea de Barros (1960) há 189 signatários, mas não lhe ocorreu informar a fonte, e os historiadores seguintes preferiram repetir o dado a consultar as edições originais. Ao historiador interessado no manifesto como irrupção pública de um coletivo de intelectuais, a variação de assinaturas é significativa. Antes de tudo porque nenhum texto é um conjunto de ideias depuradas dos suportes, nesse caso, significativamente variados. Embora o conteúdo não se altere, a variação de veículos e assinaturas, assim como de enquadramentos para as publicações, adverte que não se trata de apenas um manifesto. Note-se, por exemplo, que, no Jornal do Commercio, os títulos que anunciam, respectivamente, o futuro lançamento e o texto integral são "Mea culpa perante o povo e a mocidade" (1959, julho 5, p. 1) e "Por um ensino público obrigatório e gratuito" (1959, julho 5, p. 8), pelos quais os jornalistas acrescentaram significados. Em Memórias, por sua vez, Paschoal Lemme (1998, p. 295, grifo meu) alterou o título para "Manifesto dos educadores democratas em defesa do ensino público".

Com relação ao número de signatários, portanto, estamos longe de uma informação segura, mas há o que pensar e investigar. Se coligidas as listas de 1959, teríamos 193 diferentes nomes, dos quais apenas 58 aparecem em todas. Esse "núcleo duro" pouco supera o dobro dos 26 signatários do "Manifesto dos pioneiros", reforçando a tese de continuidade entre "pioneiros" e "educadores". Vale dizer que 21, dentre os 133 signatários da versão do Diário de Notícias, são mencionados nas cartas de Azevedo e Teixeira entre 1950 e 1960 (Vidal, 2000), evidenciando comunicação e trânsito entre as gerações, especialmente no que se refere aos quadros dos centros regionais de pesquisa, bem representados no manifesto de 1959. Uma pesquisa em volumes maiores de correspondências entre os pioneiros poderia revelar um número mais significativo de nomes, redes comuns e relações de sociabilidade entre as duas gerações de educadores. 


\section{O protagonismo da antiga geração}

Não obstante o efeito agregador de duas gerações de educadores mediante o novo manifesto, a documentação coligida indica que a geração de 1932 foi, ainda em 1959, a principal força criativa e articuladora, e que, além de Azevedo, outros pioneiros foram protagonistas na irrupção do manifesto, tendo atuado na preparação e na leitura do texto, na arregimentação de apoios e na elaboração de estratégias políticas e jornalísticas.

A correspondência entre Anísio Teixeira e Fernando de Azevedo indica que, em 1951, Anísio não se mostrava animado em reviver o movimento de 1932. O educador baiano relata que, em março de 1951, recebera telegrama de Sólon Borges dos Reis, comunicando-lhe o desejo de comemorar o vigésimo aniversário do "Manifesto dos pioneiros", com a presença dos signatários. Nas palavras de Anísio (Teixeira, como citado em Vidal, 2000, p. 67) a Fernando, a quem pede opinião sobre o assunto, em carta de 31 de março de 1951, "o manifesto é, porém, semente velha, a despeito de tudo nele ser ainda bom e são. Os pioneiros são hoje veteranos frustrados em seus sonhos de pioneiros”. Poucos meses depois, porém, em carta de 18 de maio, Anísio já considerava a possibilidade de haver um novo "movimento" reformista, em vista da reconstrução educacional: "O movimento agora devia ser por algo menos doutrinário que em 1932 e mais concreto, mais na ordem de levantamento da situação e planejamento do desenvolvimento educacional do país".

À medida que a década de 1950 se encaminhava para o último terço, Anísio passaria a comentar com frequência questões em torno do projeto de diretrizes e bases (Vidal, 2000). Iniciava-se seu crescente envolvimento na elaboração do documento, no planejamento das ações e na articulação de forças políticas. Anísio não só fez sugestões à redação, como lançou mão do conhecimento dos trâmites, de sua condição de alto funcionário do Executivo Federal e, provavelmente, de relações pessoais e familiares para arregimentar apoios. Ao menos dois conterrâneos e antigos colegas de faculdade, o advogado e jornalista Jayme Junqueira Ayres ${ }^{4}$ e o deputado Luís Viana Filho, ${ }^{5}$ desempenharam seus papéis. Ayres emitiu o parecer que negava a constitucionalidade do substitutivo Lacerda; Viana, que vinha defendendo Anísio, o Instituto Nacional de Estudos e Pesquisas Educacionais Anísio Teixeira (Inep) e o Ministério da Educação (MEC) das acusações de desenvolverem uma "campanha oculta ... contra o ensino particular" (Buffa, 1979, p. 23), encarregou-se da leitura do manifesto na Câmara. Em carta de 26 de junho, Anísio justificou a Azevedo sua escolha, em substituição a Santiago Dantas:

O debate já está na comissão, definindo-se as linhas de influência pelo Carlos Lacerda e Santiago Dantas.... Por isto mesmo, o manifesto não será lido pelo Santiago, já, de certo modo, protagonista do drama, mas pelo Luis Vianna, que, mais distante, dará ao documento o sentido de proclamação da consciência nacional do país, destinado a agir sobre o corpo deliberativo, polarizado entre as duas figuras da UDN e do PTB. (Teixeira, como citado em Vidal, 2000, p. 127).

Anísio definiu, ainda, a sequência de eventos que marcou a irrupção do manifesto. Revelando conhecimento dos trâmites, além de extrema sensibilidade para com os afetos institucionais, instruiu Azevedo a seguir os passos que seriam dados:

Quanto à publicação, penso que o manifesto só deverá vir a lume, depois de lido na Câmara. Seria esta uma homenagem dos autores à consciência do Legislativo Nacional. Acredito que V. Concorde. Nesse caso, o manifesto seria lido na 3a ou 4 a feira e publicado na 4 a ou 5 a. Somente na 2 a feira, poderei comunicar-lhe quando será feita a leitura, pois há démarches a fazer, na Câmara, para se conseguir a prioridade. (Teixeira, como citado em Vidal, 2000, p. 128).

4 O CPDOC conserva correspondências entre Anísio Teixeira e Jaime Junqueira Ayres, de 1927 a 1970, as quais revelam intensa amizade. Em carta de 13 de agosto de 1956, Ayres recorda que haviam se conhecido como calouros da Faculdade de Direito da Bahia, em 1918, que em sua casa "era recebido como um filho", e que "nenhum amigo seu foi mais incondicional e pronto [do] que eu" (Carta de Jaime Junqueira Ayres a Anísio Teixeira, 1956, agosto 13).

5 Luís Viana Filho e Anísio conheceram-se, provavelmente, na Faculdade de Direito, em 1924. Deputado constituinte em 1946, pela Bahia, Viana foi sucessivamente reeleito para as legislaturas de 1950 a 1966. 
Sua condição de executivo de órgão federal permitia-lhe o acesso a informações imprescindíveis para decisões sobre o timing do movimento, todas bem aproveitadas. Em carta de 10 de janeiro de 1959, timbrada pelo Ministério da Educação - Instituto Nacional de Estudos Pedagógicos, escreveu a Azevedo:

O outro assunto é o da Lei de Diretrizes e Bases. Adiei qualquer pronunciamento meu para o regresso dos Est. Unidos em fevereiro. A informação que tenho é de que o assunto só voltará a ser debatido no Senado, em Março. Caso porém se precipite a discussão, torna-se necessário articular São Paulo com o Rio e neste sentido pedi ao Darcy Ribeiro para se pôr em contato com você. (Teixeira, como citado em Vidal, 2000, p. 123).

O trecho revela seu comando na articulação entre São Paulo e Rio de Janeiro, fundamental para a eclosão do manifesto e para a multiplicação das assinaturas. Ainda quanto a essas, em carta de 26 de junho, Anísio (como citado em Vidal, 2000, p. 127) informa que "Paschoal [Lemme] [está] percorrendo as residências dos signatários do manifesto de 32, com os acréscimos de sua indicação e mais os que vimos aqui sugerindo. Junto a esta lista que estivemos preparando". A julgar pelo volume de adesões no Diário de Notícias, Lemme teve grande sucesso em engajar intelectuais e professores do Distrito Federal.

No dia seguinte à leitura na Câmara, Anísio (como citado em Vidal, 2000, p. 129) informava a Fernando sobre uma terceira publicação: "O Diário de Notícias publicará amanhã - 2 de julho -, na íntegra o Manifesto", para a qual, provavelmente, empenhara-se pessoalmente. Na mesma carta, prestava contas das assinaturas que conquistara, "documentando telefonemas, telegramas, entendimentos" e anexando uma lista. Por fim, o cuidado extremoso e a habilidade política de Anísio afetariam o teor do manifesto. Em carta de 26 de junho, tendo recebido cópia do texto, sugeriu, no que foi acatado, suprimir a expressão "ensine quem quiser e como puder" (Teixeira, como citado em Vidal, 2000, p. 127), porque, retirada do contexto em que ele próprio a proferira, poderia soar contraditória.

J. P. F. Carvalho (2008, p. 1) comprova, pela análise da correspondência entre Paschoal Lemme e Fernando de Azevedo, que não só a ideia de lançar um novo manifesto vinha sendo ensaiada nos anos 1950, como também "a preocupação de torná-lo um documento-memória acompanhou todas as etapas de sua elaboração até sua divulgação pública”. O autor apurou que Lemme, inconformado com a desarticulação e apatia dos educadores, vinha tentando convencer Azevedo a redigir e publicar um manifesto que retomasse as pautas daquele de que fora o "grande líder". J. P. F. Carvalho (2008) aponta que, em maio de 1959, Lemme obteve o consentimento do "cardeal", que lhe propôs uma divisão de tarefas. Ele a recusou, por não querer se afigurar diante da opinião pública como protagonista:

o movimento poderia ser de certa forma prejudicado se chegasse a saber que o manifesto tinha sido elaborado com a colaboração direta de pessoas "comprometidas" com determinadas correntes de ideias (é o meu caso) ou de outras muito visadas por correntes de opinião que ainda têm grande preponderância no País (é o caso de Anísio em relação aos católicos). (Lemme, como citado em J. P. F. Carvalho, 2008, p. 6).

Como sugere J. P. F. Carvalho (2008), embora sacrificasse sua autoria em prol do movimento, o protagonismo de Lemme mostra-se nas articulações, nas ideias e no tom que o documento viria a assumir. Em carta, Lemme sugeriu a Azevedo nomes de signatários de 1932 que poderiam aderir (Carvalho, 2008, p. 14); adiante, empenhou-se na coleta de assinaturas para as publicações em jornais do Rio. Sua invisível coautoria encontra expressão nas similaridades entre o que escreveu ao redator e o documento final, tais como os argumentos de que a causa seria suprapartidária e de que a defesa da escola pública não era uma plataforma da esquerda. Foram aceitas, além disso, suas ponderações de que o manifesto deveria ser suficientemente amplo para obter o apoio de "várias correntes de educadores progressistas, independentemente de suas convicções pessoais, políticas ou religiosas”, e que fosse depurado do "caráter de luta religiosa, ou de imposição de ideologias" (como citado em Carvalho, 2008, p. 8). 


\section{Os recursos discursivos do manifesto}

São evidentes os cuidados para com a linguagem usada na proclamação pública de sua indignação, de seus princípios e valores. Os educadores tinham consciência de que o valor da causa não se imporia, e por isso usaram recursos de enunciação para arregimentar apoios, contornar polêmicas, simular neutralidade. Os "modos de dizer" perfazem sua irrupção como um ato de fala que as exegeses, cegas à linguagem diante da beleza da causa, comumente desprezam. Nas palavras introdutórias, o manifesto expressa a vontade de "restabelecer a verdade" sem meias palavras, porque o dever não escolhe ocasião (Mais uma vez convocados, 1959, julho 1, p. 8). Adverte que não haveria veemência e brutalidade, de que "homens de espírito" não são capazes, nem o necessitam; aponta que os signatários não têm paixões ou outros interesses, nem imprimem polêmicas ou antagonismos pessoais. Senhores das palavras, portadores da razão, apresentam-se na figura do intelectual contemporâneo que, abrindo espaço na esfera pública entre governo e povo, toma-os como interlocutores. Desse espaço marginal à política pedem audição e adesão, a fim de alertar sobre o mal que se encaminha. Não se sobressaltam com o "medo" e a "ameaça" com que se tentam esconder "as necessidades e tendências reais da educação no mundo contemporâneo" (Mais uma vez convocados, 1959, julho 1, p. 8).

No entanto, o medo existe, e o texto procura vencê-lo. Os educadores falam em nome de princípios. Sua causa é maior e os princípios, universais: a verdade e a liberdade lhes impõem o dever e os obrigam à manifestação; exigem a submissão ao julgamento público de "pontos de vista sobre problemas da gravidade e complexidade com que se apresentam os da educação" (Mais uma vez convocados, 1959, julho 1, p. 8). O manifesto se coloca como revelador: decompõe o problema, retira o disfarce, desemaranha, desenreda, restabelece, reconfigura e restaura; reconstitui os fatos e a verdade. Diferentemente do Manifesto de 1932, que instalava a polêmica, o Manifesto de 1959 manipula argumentos mais próximos ao senso comum, apoiados em fatos supostamente evidentes. Os educadores apresentam-se como técnicos imprescindíveis para a solução de "dificuldades inextricáveis para quem não possa aspirar aos foros de cousa alguma em matéria de ensino e não tenha adquirido, no estudo e na prática diuturna, conhecimentos especiais e experiência na administração" (Mais uma vez convocados, 1959, julho 1, p. 8).

Essa expertise foi endossada perante a Câmara, no introito em que Luís Viana Filho enfatiza a alta qualidade dos manifestantes, "figuras das mais autorizadas no campo da educação" (Anais da Câmara dos Deputados, 1959, julho 1, p. 496), sua consciência do dever e patriotismo:

É de esperar que tão grande e valiosa contribuição ... seja recebida ... como um ato de autêntico patriotismo desses educadores que não se podiam conservar indiferentes, sob pena de serem amanhã acusados pelas gerações vindouras de não se terem colocado na trincheira a que estão obrigados. (Anais da Câmara dos Deputados, 1959, julho 1, p. 497).

A obsessão em convencer os interlocutores sobre a autoridade e a isenção dos enunciados atinge o paroxismo na convergência entre o discurso e seu primeiro suporte impresso, a publicação de $1^{\circ}$ de julho, em Oesp. Segundo o manifesto, no Brasil, as medidas de "liberdade de ensino" que isentaram o Estado de seus deveres teriam causado, em 1879, o "naufrágio do ensino superior" pelo abandono das academias e pela "diplomação elétrica" de profissionais e bacharéis; em 1911, uma "catástrofe sob todos os aspectos, inclusive o moral" (Mais uma vez convocados, 1959, p. 8). Ambas as tentativas teriam sido tão infrutíferas que os governos tiveram de recuar. A base para esse argumento é uma citação do próprio Oesp, sob o título "Liberdade de ensino remunerada". A supressão da autoria de Almeida Jr., um dos signatários e pioneiro ligado desde 1947 ao trâmite da LDB, neutraliza o discurso e faz do jornal uma fonte de opiniões "insuspeitas e autorizadas" (Mais uma vez convocados, 1959, julho 1, p. 8).

Bastante interessante é o recurso de adjetivar de "insuspeitas" as opiniões d'O Estado de $S$. Paulo, justamente por serem "autorizadas”. Mais intrigante ainda é a supressão, apenas da lista de signatários publicada no Oesp, do nome do editor-presidente dessa empresa jornalística, Júlio Mesquita 
Filho, que nas demais publicações se destaca, logo após o redator da peça. Assim como o ocultamento da autoria, a omissão servia para simular a imparcialidade do veículo, cuja "insuspeição", todavia, derrete ao exame das listas, que contêm os nomes de Paulo Duarte, braço direito do patriarca Júlio de Mesquita, redator-chefe do Oesp até 1950 e diretor da Revista Anhembi (Catani, 2009), engajada contra os interesses da Igreja e dos empresários particulares no ensino (Buffa, 1979); e de especialistas, como Fernando de Azevedo, colaborador do Oesp desde os anos 1920; Laerte Ramos de Carvalho, redator, desde 1948, da seção "notas e informações", que, em 1959, redigiu várias notas sobre a LDB e a "liberdade de ensino" (Bontempi Jr., 2015), afirmando as posições do jornal, que, não por acaso, pontuam o manifesto.

As convicções políticas dos signatários também são escamoteadas. Apenas no $10^{\circ}$ parágrafo, o sentido político-partidário da educação é aventado, mas como um enganoso lugar-comum:

a direita apoia, em geral, a escola livre, e a esquerda, a escola pública, e, por ter sido frequentemente assim, a tendência é de deslocar uma questão que se devia por em termos de interesse geral e acima dos partidos, para o terreno de uma luta religiosa, devido às suas implicações confessionais, - o que é preciso evitar por todas as formas, - ou de uma luta entre grupos políticos, igualmente prejudicial ao debate. (Mais uma vez convocados, 1959, julho 1, p. 8)

Os manifestantes não falam em nome de partidos e afirmam, a fim de contornar o partidarismo do debate, que esquerda e direita teriam se aliado no passado "por várias vezes" em defesa da escola pública. Segundo o manifesto, "somos todos os que assinamos esse manifesto, educadores republicanos e democráticos, fiéis aos mais altos valores da tradição liberal” (Mais uma vez convocados, 1959, julho 1, p. 8). Investido, igualmente, em contornar aversões entre os católicos, o manifesto traz o argumento do padre dominicano Henri Didon, designado como contrário a que se fizesse da religião um instrumento da política, e que teria dito: "nada na fé católica, nada na autoridade eclesiástica se opõe a uma opinião liberal, republicana e democrática" (Mais uma vez convocados, 1959, julho 1, p. 8). Transparece o cuidado do redator em não parecer antirreligioso ou contrário à doutrina católica, mas o uso das palavras de um sacerdote presta-se, no manifesto, a alvejar os antagonistas com o "fogo amigo".

\section{O manifesto contrário}

Mesmo com todos os cuidados retóricos dos educadores, a contrafação a seu manifesto não tardou. Contrariado, Oesp resignou-se em publicar, não na página 8 , como fizera no dia $1^{\circ}$ de julho, mas na página 21, um manifesto de 187 signatários, designados como "professores, educadores militantes e intelectuais", intitulado "Manifesto sobre as bases da educação" (1959, julho 26, p. 21). Antes de reproduzir esse texto na íntegra, o redator introduziu:

No dia 1 do corrente o "Estado" publicou, sob o título "Mais uma vez convocados", o manifesto dos educadores que se pronunciaram contra a tentativa de passar para o ensino privado as responsabilidades maiores da educação no Brasil; tentativa essa que os signatários consideraram consubstanciada em substitutivo ao projeto de Lei de Diretrizes e Bases da Educação Nacional, e que se encontra em tramitação na Câmara dos Deputados.

Acaba de ser divulgado agora outro manifesto, que exprime pontos de vista contrários ao anterior e que, em atenção a um princípio de equanimidade, o "Estado" divulga. (Manifesto sobre as bases da educação, 1959 , julho 26, p. 21).

Embora tenha sido referido por Buffa (1979), o manifesto contrário jamais ocupou a atenção da historiografia, talvez porque seu conteúdo não difira do que se costuma sumariar como "pensamento" do laicato católico e dos empresários do ensino. Entretanto, seu obscurecimento como ação coletiva, no que toca à produção do conhecimento e da memória, perfaz uma expressiva lacuna quanto à identidade dos agentes que estiveram em oposição. Seria imprescindível dispor os manifestos contrários face a face, para que, num instantâneo, pudéssemos dirimir dúvidas e projeções retrospectivas, pelas quais nomes têm sido interessadamente mostrados ou ocultados. 
Na historiografia da educação brasileira, o manifesto "Mais uma vez convocados" foi sempre abordado por seu conteúdo e, compreensivelmente, tratado por autores que concordavam com sua causa mais evidente. Não é despropositado afirmar que Barros (1960, p. XIX), que encartou o Manifesto de 1959 na Campanha em Defesa da Escola Pública, cravou para esta uma bem-sucedida interpretação dos grupos e das concepções em oposição, que se replicou até se tornar canônica:

A luta que hoje se desencadeia no país não é, como querem fazer crer certos equívocos interesses confessionais e comerciais, entre a educação pública e a particular, entre a escola oficial e a escola privada, entre uma pretensa liberdade de ensino e o monopólio estatal, mas sim entre duas filosofias, entre duas mentalidades, entre os “dois Brasis" de que nos fala Jacques Lambert.

A desqualificação dos opositores à campanha se encontra também em artigo de Florestan Fernandes (1960b, p. 83), em que afirma que os "princípios" que diziam defender não passavam de "disfarces" dos “interesses ideológicos ou pecuniários". Essa desqualificação, compreensivelmente produzida no calor da hora para fins políticos, contaminou, entretanto, a historiografia de modo indelével, desde o livro seminal de Romanelli (1986). Por essa razão, ainda hoje as biografias de educadores que tomaram o partido das "lideranças conservadoras" (Dias, 2002; Drummond, 2002; Duarte, 2019; Rabello, 2019; Warde, 2002) contra os “educadores lúcidos” omitem sua subscrição ao manifesto (por sua vez, apagado) contrário à campanha

\section{Os liberais e os socialistas: uma reinterpretação historiográfica}

Os educadores signatários do manifesto e os militantes da Campanha têm sido diferentemente assinalados pela historiografia, ainda que naquelas conjunturas suas ações e posições estivessem alinhadas. Entre as razões pelas quais isso tem ocorrido, destaco a intervenção da historiografia da educação produzida durante a ditadura, que sobre esses eventos projetou significados extraídos de acontecimentos subsequentes da história política brasileira. A significação retrospectiva e englobante, em que o Manifesto de 1959 flutua entre o fim do Estado Novo e o golpe de 1964, aparece nesta típica passagem: O Manifesto de 1959, de certa maneira, dá seqüência ao Manifesto de 1932, o complementa e atualiza, com uma visão histórica mais de vinte anos depois. As rupturas que se fariam com o movimento civil-militar de 1964, atingindo globalmente a sociedade, já se delineavam ao longo dos anos de 1950. Estes anos tinham, então, contraditoriamente, a presença ainda do passado pré-1930, a sua temporalidade própria e o futuro, o pós-64 em construção.... A direita política defendendo o ensino livre e a esquerda, o ensino público (estatal), estando aquela sob o manto de uma luta religiosa. (Sanfelice, 2007, pp. 544-549). ${ }^{6}$

O efeito mais caricato dessa superposição de tempos talvez sejam os equívocos de Pasinato (2011) e Lima (2017), que apontam Lourenço Filho e Paulo Freire entre os signatários do Manifesto de 1959, ignorando o fato de que ambos não o assinaram. Aparentemente, o primeiro nome foi depreendido da lista de 1932, enquanto o segundo, que só ganharia notoriedade após a experiência de Angicos, nos anos 1960, foi retrospectivamente associado ao pensamento progressista que a historiografia viria atribuir ao manifesto e à campanha. Em contrapartida, nenhum artigo destaca a presença de Miguel Reale, que aparece em todas as listas de signatários do manifesto. Certamente, porque, quando da intervenção política do golpe civil-militar sobre o campo intelectual, o magistrado integralista não só permaneceu à direita, como também se tornou colaborador do regime, ao passo que Paulo Freire, perseguido e exilado, veio a se tornar um ícone da esquerda brasileira.

6 A premissa está presente em História da educação brasileira, sucesso editorial dos anos 1980. Ribeiro (1992, p. 146), cujo oitavo capítulo tem como subtítulo "O significado da crise: o período anterior ao golpe de 1964", omite o manifesto de 1959 e explica as ideias dos "defensores da escola pública" recorrendo ao de 1932. 
Foi visto que Roque Spencer, no calor da hora, apoiou-se na tese sociológica formulada por Jacques Lambert, em Os dois Brasis, que afirma coexistência de "idades históricas diversas" no país. Segundo o autor (1969, p. 105), "entre o velho Brasil e o novo existem séculos de distância; no correr dos anos a diferença dos ritmos de evolução ocasionou a formação de duas sociedades, diferentes porque não são contemporâneas". A apropriação das categorias "moderno" e "arcaico" para definir as posições em torno da LDB constitui o fio que ata o movimento renovador à Campanha em Defesa da Escola Pública, até porque atualiza a bem aceita explicação que Fernando de Azevedo (1971) consagrara para os anos 1920 e 1930, de que o debate em torno da escola nova se reduzia à oposição entre "pioneiros" e "católicos", o "novo" e o "velho" (Carvalho, 1989).

Sustentado na tese de que a formação histórica de uma sociedade complexa, mais populosa, urbanizada e industrial demandaria novas formas e conteúdos educativos (Bontempi Jr., 2005), Azevedo exalta os renovadores pela lúcida concatenação aos tempos presente e futuro e condena os católicos pela insistência em pugnar por valores de um passado que a nação precisava superar. Do mesmo modo, na volumosa polêmica contra o substitutivo Lacerda, os defensores da escola pública se representavam como sabedores e portadores dos valores e medidas educativas convenientes ao mundo moderno, urbano, tecnológico e industrial, cuja adoção seria necessária para sociedades que se quisessem avançadas, desenvolvidas e democráticas (Barros, 1960).

A tendência da democratização do ensino, bandeira unificadora dos intelectuais educadores de 1959 e 1960, era compreendida por Florestan Fernandes (1960a, pp. 154-155) como "requisito da ordem social democrática" e "fator de seu aperfeiçoamento". Contida ou solapada por toda a história pregressa, essa tendência, se liberada, lograria "adaptar o sistema de ensino herdado do passado aristocrático às exigências educacionais do presente” (1960a, p. 159, grifo meu). Para Florestan (1960a, p. 159, grifo meu), a democratização do ensino viria "ajustar a educação aos requisitos econômicos, políticos, sociais e culturais da ordem societária vinculada ao regime democrático, à economia mecanizada e à civilização tecnológico-industrial”. Trata-se, como em Azevedo, de agir para sincronizar o movimento educacional ao desenvolvimento da sociedade, de modo a realizar a interpretação sociológica de sua relação (Bontempi Jr., 2005); como em Azevedo e Barros, os opositores resistem ao devir e defendem uma ordem anacrônica.

O uso dos termos "adaptar” e "ajustar”, referidos às relações entre educação e sociedade, é central na produção militante de Florestan nos anos 1950, quando aluno e professor da Universidade de São Paulo (USP) e na condição de "devedor da tradição sociológica funcionalista", pela qual buscava uma cientificidade afinada "com o processo de modernização pelo qual passava a sociedade brasileira" (Ridenti, 1998, p. 172). De acordo com Ridenti (2003, p. 201), na intelectualidade e nos movimentos sociais a que se associavam prevaleciam "a luta contra o poder remanescente das oligarquias rurais e suas manifestações políticas e culturais", um otimismo modernizador e o insurgente "impulso revolucionário, alimentado por movimentos sociais e portador de ambiguidades nas propostas de revolução brasileira, democrático-burguesa (de libertação nacional), ou socialista, com diversas gradações intermediárias".

A partir da segunda metade da década de 1960, a radicalidade do golpe civil-militar e a repressão instaurada impuseram aos movimentos sociais e ao estudantil, em particular, o recolhimento de suas bandeiras, ao passo que agudizaram a polarização entre intelectuais, premidos pela definição de suas posições entre direita e esquerda. No ambiente universitário, como relata Maria Luísa Santos Ribeiro (1999, pp. 124-125), esse foi o momento em que "muitos dos antigos militantes voltaram-se mais para a dimensão interna da luta, que era a de operar transformações na estrutura do ensino superior", ou seja, promover a formação de educadores "à luz dos interesses e das condições objetivas e subjetivas da maioria da população brasileira". Surgiram, na virada da década de 1970, os programas de pós-graduação em universidades relativamente protegidas dos expurgos promovidos pelo regime, como o mestrado em Filosofia da Educação da Pontifícia Universidade Católica de São Paulo, em que 
professores e estudantes da esquerda vieram a completar sua formação sob a orientação de Casemiro dos Reis Filho e Dermeval Saviani. Maria Luísa Ribeiro (1999, p. 125) definiu, como ponto de viragem que marcou sua geração, a contraposição a uma concepção idealista da realidade brasileira:

Assim é que, para alguns (dentre os quais me incluía) foi ficando claro que, do ponto de vista filosófico, o que fundamentalmente estava sendo posto em questão era uma concepção idealista sobre a realidade brasileira. Necessário se fazia, então, buscar uma formação teórica mais rigorosa de base materialista-dialética, apesar da censura após o golpe de 1964.

Essa atitude geracional acompanhava a tendência de movimentos e partidos de esquerda durante o período da Guerra Fria, aos quais aderiram intelectuais e artistas que valorizavam a ação para mudar a história e promover a construção do homem novo, cujo modelo estaria no passado, em raízes étnicas e sociais reclusas e a salvo dos males da modernização capitalista. "Em suma, buscava-se no passado uma cultura popular autêntica para construir uma nova nação, ao mesmo tempo moderna e desalienada, no limite, socialista" (Ridenti, 2003, p. 198).

Mais de uma década após ter defendido o mestrado naquele programa, Paulo Ghiraldelli Jr. (1999, p. 71) criticou sua geração pela pretensão de romper com a ideologia e revelar a história e o mundo social objetivo. Para Ghiraldelli, os historiadores da educação orientados pelo materialismo histórico entendiam-se providos da liberdade e da radicalidade inerentes ao "polo epistemologicamente privilegiado da crítica”, ou seja, à base da pirâmide social. Assim instalada ao lado do povo, na qualidade autoconferida de “'intelectuais de função', como diria Gramsci” (Ribeiro, 1999, p. 139), a historiografia assumiu seu caráter militante e esgrimiu, com relação à memória e à história da educação brasileira, deslocamentos que conferiram novos significados para o movimento renovador dos anos 1920 e 1930 e para as manifestações dos educadores de fins da década de 1950. De modo sintético, nessas novas narrativas os "pioneiros" viram-se empurrados ao denso lodaçal de ausências e fracassos do passado educacional republicano e acusados do mesmo conservantismo aristocrático com que desqualificavam seus adversários; por seu turno, uma leitura retrospectiva da cultura política dos anos 1950, à luz das posições tomadas a partir da década seguinte pelos que se uniram pela escola pública, permitiu sua separação triádica, pela qual os "socialistas" foram salvos da areia movediça que tragaria os demais para o lado opaco da história.

O primeiro passo dado para essa dobra deu-se antes que a primeira dissertação fosse defendida nos programas, nos textos de combate publicados por Florestan Fernandes durante a Campanha em Defesa da Escola Pública. Em “A democratização do ensino", Fernandes (1960b, p. 156), para apoiar sua tese sobre a inadequação da sociedade brasileira aos ditames do ajuste pela educação democrática, assenta que, entre 1889 e 1950, "a República não teve sucesso na esfera propriamente pedagógica. Não impôs novos ideais e novos valores educacionais, que visassem organizar a escola segundo o novo modelo de homem, exigido pela ordem social democrática”. Ao fazê-lo, atirou a primeira pedra ao edifício da memória positiva do movimento "renovador" da escola nova, desconstruído paulatinamente ao fluir das obras que consolidaram a história e a memória da educação brasileira segundo o materialismo histórico, que se faria hegemônico nos programas de pós-graduação em educação entre os anos 1970 e 1980.

Essa historiografia abraçou a tese de que, como educadores profissionais, os escolanovistas teriam reduzido o legado de um programa amplo de ação educativa, em que questões educacionais eram analisadas à luz de fundamentos históricos-sociais, a um programa de formação de viés "tecnicista", em que vieram a ser tratadas como domínio especializado e alienado. Empenhada em comprovar na história a leitura de Florestan, de que jamais as classes dominantes haviam permitido a disseminação de uma educação libertadora das classes populares, essa geração inverteu o significado da ação dos pioneiros, de progressista para conservadora, assim como identificou seus enunciados pedagógicos como um véu ideológico a encobrir a rearticulação da hegemonia burguesa, pela qual se negava, mais uma vez, a proposição de uma escola para o povo (Brandão, 1999). 
Quanto à memória dos movimentos de 1959 e 1960, sua outra significação se expressa na narrativa de Saviani (1996) sobre a participação de Florestan na Campanha em Defesa da Escola Pública. Procurando salientar a "unidade e coerência" da trajetória do sociólogo, Saviani (1996, p. 83) consegue apartá-lo daquele coletivo intelectual, por meio da classificação dos participantes em "três grupos distintos: os liberais-pragmatistas, os liberais-idealistas e os de tendência socialista” (1996, p. 79). Conforme suas categorias, o primeiro grupo provinha do movimento da escola nova; o segundo era formado por professores da USP ligados ao O Estado de S. Paulo, nomeadamente Roque Spencer, Laerte Ramos de Carvalho e João Eduardo Villalobos, além do próprio Julio de Mesquita Filho; o terceiro, por Florestan Fernandes, Fernando Henrique Cardoso, Octavio Ianni e Wilson Cantoni, que se diferenciaria por entender "a educação em suas relações recíprocas com a sociedade, o que significa que o processo educativo deve ser dirigido não apenas à adaptação mas à transformação social” (Saviani, 1996, p. 80). Essa interpretação, ao enfatizar as diferenças no interior de uma frente ampla, não só imobiliza o movimento da consciência de uma geração, como também minimiza as diferenças entre o que Florestan pensava entre 1959 e 1962, quando os redigiu, e 1966, quando, sob o impacto do golpe de Estado, recompilou e prefaciou seus textos de combate e polêmica em Educação e sociedade no Brasil (Fernandes, 1966).

A deterioração da identidade de Florestan para com os "liberais-idealistas" pode não ter ocorrido durante a Campanha, como pretendeu Saviani, mas, particularmente com relação a Roque Spencer e Laerte Ramos de Carvalho, no transcorrer de uma polêmica que, como uspianos, travaram em torno da reforma dos estatutos da universidade, entre os anos 1962 e 1969. Florestan, mais afeito às pautas do movimento estudantil do que à concepção dos catedráticos, foi um dos que, tendo participado das comissões paritárias para a reformulação dos estatutos, criticou a concepção idealista, "alienada e elitista" do memorial que a comissão de reestruturação, presidida por seu ex-companheiro de Campanha, Roque Spencer, apresentou em junho de 1968, ao fim de 18 meses de trabalho. Como é sabido, o relatório foi "atropelado" pela Lei Federal n. 5.540/1968 e pelo Decreto Estadual n. 52.326/1969, que baixou os estatutos da USP (Cunha, 1988, p. 150), assim como o foram as propostas das comissões paritárias, motivadas por insatisfações de diversas ordens que revelaram ou acentuaram divergências inconciliáveis entre sujeitos posicionados, não apenas em espectros político-ideológicos opostos, mas também em diferentes categorias, carreiras e poderes institucionais do mundo universitário: estudantes, auxiliares de ensino, catedráticos (Cunha, 1988).

Quanto a Laerte Ramos de Carvalho, com quem Florestan mantinha relações pessoais muito estreitas, o distanciamento foi marcado pela experiência desastrosa de seu reitorado da Universidade de Brasília, em que figurou como protagonista da demissão de "subversivos" e, por extensão, do processo conflituoso que levou ao sepultamento do sonho de realização da universidade de Anísio Teixeira e Darcy Ribeiro (Bontempi Jr., 2018). É provável que tenha sido nesses momentos, e não durante os tempos de militância comum em defesa da escola pública, que afloraram divergências profundas entre o socialista Florestan e os liberais-idealistas Roque Spencer e Laerte Ramos. A visada pelo retrovisor, entretanto, fez-nos projetar sobre o manifesto e a campanha as diferenças radicalizadas no tempo da ditatura, de modo a definir a defesa da escola pública como plataforma da esquerda socialista, ao contrário, aliás, do consenso liberal-democrático que o movimento coletivo dos intelectuais afirmara no Manifesto de 1959.

\section{Considerações finais}

Mediante o Manifesto de 1959, um coletivo de educadores gerou uma causa, escolheu interlocutores e adversários; produziu um discurso calculado para provocar adesões e, sobretudo, para afetar a opinião pública, intimidar adversários e pressionar governo e congressistas a tomar partido de seus princípios e intenções. Essas estratégias, coletivas e dinâmicas, compuseram-se de astúcias na administração do tempo, de veículos e atos públicos, ditos e omissões em ocasiões oportunas, assinaturas adicionadas e 
excluídas, e citações e recorrências em vista de efeitos estudados. Em suas formas de materialização, o manifesto endereçou estratégias de produção de identidades, autoridade, isenção, consenso, etc., cujas implicações transbordam os limites da exegese e abrem espaço aos problemas da história intelectual e da história do pensamento político, relacionados ao manifesto como acontecimento singular, e aos campos de força que em torno dele - e contra ele - se formaram e dispuseram os sujeitos em ação na imprensa e sobre a opinião pública, no Legislativo, nas entidades civis e nas instituições de ensino.

Apoiado no estudo de J. P. F. Carvalho (2008), sugeri que, se é consensual que a geração dos anos 1940-1960, de Laerte Ramos de Carvalho, Roque Spencer, Darcy Ribeiro e Florestan Fernandes, tenha liderado a Campanha em Defesa da Escola Pública, foram os pioneiros de 1932 os principais protagonistas do Manifesto de 1959. Apontei, entretanto, que a estratégia de apresentá-lo como "um segundo manifesto", a fim de lhe dar maior legitimidade perante a opinião pública, acabou por reforçar aos olhos dos historiadores da educação a dependência, que se complementa com sua redução a evento antecedente da Campanha de 1960 e do que viria a suceder no país logo após 1964. Lancei, além disso, a hipótese de que os recursos discursivos do manifesto e do aparato noticioso-propagandístico que acompanhou sua irrupção encantaram os historiadores pósteros, que, tendo assumido suas pautas como "progressistas" ou "socialistas", lançaram-se a distribuir nos campos opostos, afetiva e retrospectivamente, sujeitos e valores, e a tomar o texto como portador de uma mensagem atemporal, em vez de lhe conferir a historicidade que remete o evento e seus agentes a seu próprio tempo, face a face com seus efetivos antagonistas.

Avaliei o impacto de textos e eventos, quer sobre a produção historiográfica, quer sobre a cultura política das sucessivas épocas, para indicar que os anos que se situam entre a eclosão do manifesto de 1959 e a reforma universitária de 1968 apresentam uma notável riqueza de acontecimentos significativos para a sensibilidade política dos intelectuais que neles se envolveram ou que por eles foram afetados. Descomprimir esse curto espaço de tempo, fragmentando a escala e a abrangência explicativa do tempo histórico usualmente recorrido para explicar aquela cultura política e a historiografia sobre a qual se projeta, faz emergir a ressonância imediata entre os sujeitos dos eventos que, de modo relativamente rápido, reconfiguraram o campo intelectual brasileiro e, particularmente, aqueles que mais se envolveram com a educação e sua história.

\section{Referências}

Alves, C. (2012). Jean-François Sirinelli e o político como terreno da história cultural. In E. M. T. Lopes, \& L. M. Faria Filho (Org.), Pensadores sociais e a história da educação II (pp. 111-134). Autêntica.

Anais da Câmara dos Deputados (1959, julho 1). O sr. Luiz Vianna (para uma comunicação). 68a Sessão da Câmara dos Deputados, de 30 de junho de 1959, pp. 496-512. https://imagem.camara.leg.br/dc_20b.asp\#/

Azevedo, F. (1959). Mais uma vez convocados (Manifesto ao povo e ao Govêrno). Revista Brasileira de Estudos Pedagógicos, 31(74), 8-24.

Azevedo, F. (1971). A cultura brasileira (5a. ed.). Melhoramentos.

Barros, R. S. M. (Org.). (1960). Diretrizes e bases da educação. Pioneira.

Bomeny, H. Manifesto "Mais uma vez convocados". https://cpdoc.fgv.br/producao/dossies/JK/artigos/ Educacao/ManifestoMaisUmaVez.

Bontempi Jr., B. (2005). A presença visível e invisível de Durkheim na historiografia da educação brasileira. In L. M. Faria Filho (Org.), Pensadores sociais e história da educação (pp. 47-62). Autêntica.

Bontempi Jr., B. (2015). Laerte Ramos de Carvalho e a constituição da História e Filosofia da Educação como disciplina acadêmica. Edufu.

Bontempi Jr., B. (2018). Laerte Ramos de Carvalho (1922-1972). A educação pela presença. In T. C. Rego. Educadores brasileiros: Ideias e ações de nomes que marcaram a educação nacional (pp. 197-208). CRV. 
Brandão, Z. (1999). A intelligentsia educacional: Um percurso com Paschoal Lemme por entre as memórias e as histórias da escola nova no Brasil. Edusf.

Buffa, E. (1979). Ideologias em conflito: Escola pública e escola privada. Cortez \& Moraes.

Carta de Jaime Junqueira Ayres a Anísio Teixeira (1956, agosto 13). Correspondência entre Jaime Junqueira Aires e Anísio Teixeira sobre assuntos diversos. Arquivo do CPDOC. Classificação: AT c 1927.09.26/2. Série: c Correspondência. Data de produção: 26/09/1927 a 19/06/1970. Quantidade de documentos: 23 (67 folhas).

Carvalho, J. P. F. (2008, maio). A origem do Manifesto dos educadores mais uma vez convocados, de 1959, na correspondência de alguns de seus signatários. [Apresentação de comunicação]. Congresso Brasileiro de História da Educação. Aracaju, Brasil. Unit/Ufes, pp. 1-15.

Carvalho, M. M. C. (1989). O novo, o velho, o perigoso: relendo a cultura brasileira. Cadernos de Pesquisa, 71, 29-35.

Catani, A. M. (2009). A Revista de Cultura Anhembi (1950-62): Um projeto elitista para elevar o nivel cultural no Brasil. Eduem.

Charle, C. (1990). Naissance des "intellectuels" (1880-1900). Minuit.

Cunha, L. A. (1983). A universidade critica: O ensino superior na República Populista. Francisco Alves.

Cunha, L. A. (1988). A universidade reformanda. Francisco Alves.

Diário do Congresso Nacional (1959, julho 1). 68a Sessão da Câmara dos Deputados, do dia 30 de junho de 1959, pp. 3691-3695.

Dias, J. A. Carlos Pasquale. (2002). In M. L. A. Fávero, \& J. M. Britto (Org.), Dicionário de educadores no Brasil: Da colônia aos dias atuais (2a. ed., pp. 225-229). Editora UFRJ/MEC-Inep-Comped.

Drummond, A. A. José Carlos de Mello e Souza. (2002). In M. L. A. Fávero, \& J. M. Britto (Org.), Dicionário de educadores no Brasil: Da colônia aos dias atuais (2a. ed., pp. 587-594). Editora UFRJ/MEC-Inep-Comped.

Duarte, R. A. (2019). Carolina Ribeiro: o lugar da mulher na educação em São Paulo. In D. G. Vidal, \& P. P. Vicentini (Org.), Mulheres inovadoras no ensino (São Paulo, séculos XIX e XX) (pp. 83-96). Fino Traço. Escola pública é o único patrimônio para nossa consolidação democrática. (1959, junho 23). Correio Paulistano, p. 9. Arquivo IEB-USP. Fundo Fernando de Azevedo/ Cx. 085/Coleção Atividades Profissionais/FA-D9/1, 33. Fernandes, F. (1960a). A posição dos escritores. In R. S. M. Barros (Org.), Diretrizes e bases da educação nacional (pp. 85-92). Pioneira.

Fernandes, F. (1960b). A democratização do ensino. In R. S. M. Barros (Org.), Diretrizes e bases da educação nacional (pp. 154-165). Pioneira.

Fernandes, F. (1966). Educação e sociedade no Brasil. Dominus/Edusp.

Ghiraldelli Jr., P. (1999). Posso conversar sobre "história das idéias" e "história da educação" a partir do neopragmatismo de Richard Rorty? In C. Monarcha (Org.), História da educação brasileira: A formação do campo (pp. 65-94). Unijuí.

Lambert, J. (1969). Os dois Brasil (5a. ed.). Companhia Editora Nacional.

Lemme, P. (1988). Memórias (Vol. 4). Inep.

Lima, V. L. S. (2017). Os manifestos de 1932 e 1959 e suas contribuições para as diretrizes e bases da educação. Revista Communitas, 1(1), 247-267.

Mais uma vez convocados. Manifesto ao povo e ao governo. (1959, julho 1). O Estado de S. Paulo, p. 8.

Manifesto dos educadores em princípio de julho. (1959, junho 20). O Estado de S. Paulo, p. 11 (recorte). Arquivo IEB-USP. Fundo Fernando de Azevedo/Cx. 085/Coleção Atividades Profissionais/FA-D9/1, 31.

Manifesto dos educadores mais uma vez convocados. (1959, julho 2). Diário de Notícias, p. 6, segunda seção. 
Manifesto público dos educadores para reafirmação de princípios diante dos problemas educacionais. (1959, junho 18). Folha da Manhã, s.p. (recorte). Arquivo IEB-USP. Fundo Fernando de Azevedo/Cx. 085/ Coleção Atividades Profissionais/FA-D9/1, 30.

Manifesto sobre as bases da educação. (1959, julho 26). O Estado de S. Paulo, p. 21.

Manifestos dos pioneiros da educação nova (1932) e dos educadores (1959). (2010). Fernando de Azevedo et al. Recife, PE: Fundação Joaquim Nabuco; Massangana.

Manuscrito de Fernando de Azevedo: "Manifesto dos educadores mais uma vez convocados", publicado em vários jornais e revistas em 1959 (primeiro exemplar). 24 p. (datilografado). Arquivo IEB-USP. Fundo Fernando de Azevedo/Cx. 085/Coleção Atividades Profissionais/FA-D9/1, 14a.

Mea culpa perante o povo e a mocidade. (1959, julho 2). Jornal do Commercio, p. 1.

Pasinato, D. (2011). Importância do manifesto de 1959 para a educação brasileira. Revista Semina, 10(1), 1-12.

Por um ensino público obrigatório e gratuito. (1959, julho 5). Jornal do Commercio, p. 8-9.

Rabello, R. S. (2019). Noemy da Silveira Rudolfer e a vanguarda da psicologia educacional. In D. G. Vidal, \& P. P. Vicentini (Org.), Mulheres inovadoras no ensino (São Paulo, séculos XIX e XX) (pp. 219-240). Fino Traço.

Ribeiro, M. L. S. (1992). História da educação brasileira: Organização escolar (12a. ed.). Cortez.

Ribeiro, M. L. S. (1999). A reconstrução do texto histórico em educação no contexto da sociedade brasileira: minha experiência nesse processo. In C. Monarcha (Org.), História da educação brasileira: A formação do campo (pp. 121-146). Unijuí.

Ridenti, M. (2003). Cultura e política brasileira: enterrar os anos 60? In E. R. Bastos, M. Ridenti, \& D. Rolland (Org.), Intelectuais: Sociedade e política, Brasil-França (pp. 197-212). Cortez.

Ridenti, M. (1998). Um romantismo revolucionário em Florestan Fernandes? In P. H. Martinez (Org.), Florestan ou o entido das coisas (pp. 169-176). Boitempo.

Romanelli, O. O. (1986). História da educação no Brasil (1930-1977) (8a. ed.). Vozes.

Sanfelice, J. L. (2007). O Manifesto dos educadores (1959) à luz da história. Revista Educação e Sociedade, 28(99), 542-557.

Saviani, D. (1996). Florestan Fernandes e a educação. Estudos Avançados, 10(26), 71-87.

Sirinelli, J.-F. (1986). Le hasard ou la nècessité? Une histoire enchantier: l'histoire des intellectuels. Vingtième Siècle, Revue d'Histoire, 9, 97-108.

Sirinelli, J.-F. (2003). Os intelectuais. In R. Rémond. Por uma história politica (pp. 231-269). FGV.

Skinner, Q. (2005). Visóes da política: Sobre os métodos históricos. Difel.

Vidal D. G. (Org.). (2000). Na batalha da educação: Correspondência entre Anisio Teixeira e Fernando de Azevedo (1929-1971). Edusf.

Vieira, C. E. (2017). Contextualismo linguístico: contexto histórico, pressupostos teóricos e contribuições para a escrita da história da educação. Revista Brasileira de História da Educação, 17(3) (46), 31-55.

Warde, M. J. (2002). Noemy da Silveira Rudolfer. In M. L. A. Fávero, \& J. M. Britto (Org.), Dicionário de educadores no Brasil: Da colônia aos dias atuais (2a. ed., pp. 860-866). Editora UFRJ/MEC-Inep-Comped.

Warde, M. J. (2004). Legado e legatários: Questões sobre o Manifesto dos pioneiros da educação nova. In M. C. Xavier (Org.), Manifesto dos pioneiros da educação: Um legado educacional em debate (pp. 221-240). Editora FGV.

Xavier, L. N. (2015). O manifesto de 1932 e a democracia como valor universal. Revista Brasileira de Estudos Pedagógicos, 96 (n. especial), 133-156. 
Fontes para consulta

Luís Viana Filho. Perfil do Acadêmico. Academia Brasileira de Letras. http://www.academia.org.br/academicos/ luis-viana-filho.

Verbete biográfico "Viana Filho, Luís". Arquivo do CPDOC. https:/www.fgv.br/cpdoc/acervo/dicionarios/ verbete-biografico/viana-filho-luis.

\section{Disponibilidade de dados}

Os dados subjacentes ao texto da pesquisa estão informados no artigo.

\section{Como citar este artigo}

Bontempi Jr., B. (2021). O Manifesto dos Educadores de 1959 revisitado: Evento, narrativas e discursos. Cadernos de Pesquisa, 51, Artigo e07278. https://doi.org/10.1590/198053147278

Recebido em: 06 ABRIL 2020 | Aprovado para publicação em: 07 OUTUBRO 2020 